\title{
Item test analysis to assess the difficulty index for biostatistics, epidemiology, and demography module of undergraduate medical students of Raipur, Chhattisgarh, India
}

\begin{abstract}
Verma N. ${ }^{1}$, Shinkar S. ${ }^{*}$, Jain $\mathrm{K}^{3}$
DOI: https://doi.org/10.17511/ijphr.2020.i06.04

${ }^{1}$ Nirmal Verma, Professor, Department of Community Medicine, Pt. J. N. M. Medical College, Raipur, Chhattisgarh, India.

2* Swapnil Shinkar, Statistician Cum Lecturer, Department of Community Medicine, Pt. J. N. M. Medical College, Raipur, Chhattisgarh, India.

${ }^{3}$ Kamlesh Jain, Professor, Department of Community Medicine, Pt. J. N. M. Medical College, Raipur, Chhattisgarh, India.

Background: "Psychometry" has been developed as a branch of psychology that deals with the measurement of psychological traits or mental abilities like intelligence, aptitude, opinion, interest, personality, or scholastic achievement. Term Examination or Test series are being increasingly used in such an assessment. "Item Analysis" examines student responses to individual test items to assess the quality of those items and test as a whole to improve or revise items and the test. Objective: To assess the difficulty Index of third-year undergraduate students towards the biostatistics, epidemiology, and demography module. Materials and Methods: This is a crosssectional observational study was conducted among 130 undergraduate medical students for Internal and External examination using a set of 3 questions related to the Biostatistics, Epidemiology and Demography module after 25 hours of teaching. Data were collected and entered in Microsoft Excel and analyzed using IBM SPSS version 23.0 software. Results: The majority of study subjects were females (57.7\%), Hindu by religion (90.0\%), studied in English Medium School (79.2\%). Only $14.6 \%$ of them took Biology with Mathematics subjects during higher secondary studies. Approximately $52.3 \%, 78.5 \%$, and $74.5 \%$ of study subjects correctly solved questions of Biostatistics, Epidemiology, and Demography in the External Examination. The Difficulty of Biostatistics relative to Epidemiology was 7.3 times higher than the Epidemiology relative to Demography in the External Examination. Conclusion: Biostatistics module was more difficult than other modules for Undergraduate medical students.
\end{abstract}

Keywords: Difficulty Index, Biostatistics, Epidemiology, Demography

Corresponding Author

Swapnil Shinkar, Statistician Cum Lecturer, Department of Community Medicine, Pt. J. N. M. Medical College, Raipur, Chhattisgarh, India. Email: shinkars2008@gmail.com

\section{How to Cite this Article}

Verma N, Shinkar S, Jain K. Item test analysis to assess the difficulty index for biostatistics, epidemiology, and demography module of undergraduate medical students of Raipur, Chhattisgarh, India. Public Health Rev Int J Public Health Res. 2020;7(6):66-70.

Available From

https://publichealth.medresearch.in/index.php/ijphr/ article/view/150
To Browse

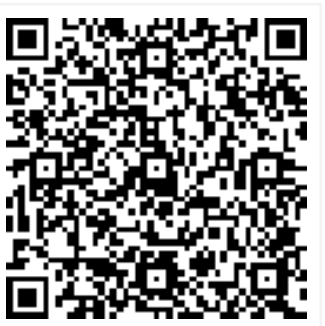

Manuscript Received 2020-12-14

Conflict of Interest No
Review Round 1 2020-12-21

Funding

Nil

Review Round 2
$2020-12-25$
Ethical Approval
Yes

Review Round 2

Yes
Review Round 3

Plagiarism X-checker $5 \%$
Accepted 2020-12-29

Note

(c) 2020 by Nirmal Verma, Swapnil Shinkar, Kamlesh Jain and Published by Siddharth Health Research and Social Welfare Society. This is an Open Access article licensed under a Creative Commons Attribution 4.0 International License https://creativecommons.org/licenses/by/4.0/ unported [CC BY 4.0]. 


\section{Introduction}

Croxton and Cowden defined "statistics as a science which deals with the collection, classification, analysis, interpretation, and presentations of numerical data" and its application to the biological field or medical field is called biostatistics [1].

The role of biostatistics, epidemiology, and demography is well recognized in the curriculum of undergraduate medical schools or colleges in developed and developing countries [2].

Biostatistics, epidemiology, and demography are taught together in the third year (MBBS Final part 1) at university Ayush Raipur as a course is offered under the community medicine discipline.

The objective of this course is

01 . To enable the medical student to understand the language and principle of biostatistics, epidemiology, and demography.

02. To highlight the nature and the distribution of disease.

03. To teach students to design their research project as well as to able to critically read and understand scientific papers in medical journals.

Thus, it covers the basic theoretical concept of biostatistics, epidemiology, and demography along with practical sessions.

The sequence of the topics was carefully observed so that biostatistics, epidemiology, and demography are taught in a parallel manner to amalgamate the knowledge of the topics which lectures were followed by practical sessions when applicable.

Purpose of the Study: Assessment of Undergraduate medical students gives insight into their learning and competencies. Term Examination or Test series are being increasingly used in such an assessment.

"Item Analysis" examines student responses to individual test items to assess the quality of those items and test as a whole to improve or revise items and the test [3-5].

"Psychometry" has been developed as a branch of psychology that deals with the measurement of psychological traits or mental abilities like intelligence, aptitude, opinion, interest, personality, or scholastic achievement [6].
Scaling Individual Test Items in terms of Difficulty: In this study 3 problem was assign in the test, out of this 1 problem was related to biostatistics, 1 was Epidemiology and 1 was Demography or Vital Statistics were administered to a large group of individuals/subjects who was selected as per inclusion or exclusion criteria.

For this, the set of problems was given to a group of individuals/subjects for solving them, and for each problem, the proportion of those who could solve it is obtained. i.e.

$\mathrm{P}=$ (No. of subjects answering problem correctly)/ (Total No.of Subjects)

Thus items can be arranged in order of "percentage difficulty". But the comparison of percentage difficulty is only a crude method. Since these percentages do not successfully reflect the difference in difficulty.

In the construction of difficulty, the index assumes that the measurement of psychological traits being is distributed normally without loss of generality about mean is zero and variability of the group provides a better difficulty index known as sigma index.

The main objective of the current study was to assess the difficulty Index of the third year (MBBS Final Part I) undergraduate students towards the biostatistics, epidemiology, and demography module.

\section{Material and Methods}

Since the inception of the Pt. J. N. M. Medical College in 1969 affiliated with Pt. Deen Dayal Upadhyay Memorial Health Science and Ayush University of Chhattisgarh, since 2009, the community medicine department has been conducting Biostatistics, Epidemiology and Demography module in the undergraduate medical curriculum with involving exposure to the community in the form of field visits and family assignments, accompanied by the critical reading of medical literature.

University has been examining community medicine subjects by the end of the seventh semester.

Study Design: Cross-Sectional observational study design was used.

Participants / Individuals: The study was conducted at Pt. J. N. M. Medical College, Raipur 
(CG), after obtaining informed consent from all the participants, during the period from January 2020 to March 2020.

A self-administered subjective questionnaire was used to collect data for the study. The sociodemographic questionnaire was mailed to all third year (MBBS Final part I) students. A total of 130 students have participated, $55(42.3 \%)$ males and $75(57.7 \%)$ females participated in the study selected by universal sampling.

The researchers initially reviewed the curriculum of undergraduate medical courses in general, as well as Biostatistics, Epidemiology, and Demography in particular.

Inclusion Criteria: All the third year (MBBS Final part I) students who were admitted in the 2016 batch.

Exclusion Criteria: Those who did not give verbal consent and who were not admitted in the 2016 batch (i.e. repeater or admitted on before 2016 batch).

Statistical Analysis: Data entry and analysis was done using computer software like Microsoft Excel \& IBM SPSS Version 23.0. Frequencies or percentages have been presented for categorical variables. Difficulty Index was used to compare the Biostatistics, Epidemiology, and Demography Module.

The aim of the study was explained to the third year (MBBS part I) students and they were informed that participation was voluntary. The questionnaire was administered in 2019 after completion of the community medicine module.

\section{Results}

A total of 130 students participated in the study. The majority of the students were females $(57.7 \%)$, $79.2 \%$ of the students were studied in English medium in the 12th class. The majority of the students were Hindu (90.0\%), few of the students have studied biology with mathematics in the 12th class $(14.6 \%)$. The majority $90.0 \%$ of the students were attended more than 60 percent classes and $72.3 \%$ of the students were taken more than 2 attempts for NEET Examination (Table 1). The mean age of the participant was 22 years along the standard deviation was 1.4 years. The Minimum and Maximum age were 20 - 30 years.
Variables of the Study Participants.

\begin{tabular}{|l|l|l|l|}
\hline \multicolumn{2}{|c|}{ Variables } & Frequencies & Percentage \\
\hline \multirow{4}{*}{ Gender } & Male & 55 & 42.3 \\
\cline { 2 - 4 } & Female & 75 & 57.7 \\
\hline \multirow{4}{*}{ Religion } & Christian & 8 & 6.2 \\
\cline { 2 - 4 } & Hindu & 117 & 90.0 \\
\cline { 2 - 4 } & Muslim & 1 & 0.8 \\
\cline { 2 - 4 } & Other & 4 & 3.0 \\
\hline \multirow{3}{*}{ 12th Class Subject } & Biology & 103 & 79.2 \\
\cline { 2 - 4 } & Biology + Mathematics & 19 & 20.8 \\
\cline { 2 - 4 } & Hindi & 27 & 85.4 \\
\hline \multirow{3}{*}{ Attendance } & Less Than $60 \%$ & 13 & 10.0 \\
\cline { 2 - 4 } & More Than $60 \%$ & 117 & 90.0 \\
\hline \multirow{3}{*}{ NEET Exam Attempt } & Less Than 2 & 36 & 27.7 \\
\cline { 2 - 4 } & More Than 2 & 94 & 72.3 \\
\hline
\end{tabular}

Out of the total of 130 students, $35.4 \%$ of the students were correctly solved Biostatistics Section, $49.2 \%$ of the students were correctly solved Epidemiology Section and $52.3 \%$ of the students have correctly solved the Demography section in the Internal Examination. Also, 52.3\% of the students were correctly solved Biostatistics Section, $78.5 \%$ of the students were correctly solved Epidemiology Section and $75.4 \%$ of the students have correctly solved in Demography section the External Examination. (Table 2).

Table-2: Distribution of the participants of correctly solving the problems in the Biostatistics, Epidemiology, and Demography Module.

\begin{tabular}{|c|l|l|l|}
\hline Examination & \multicolumn{1}{|c|}{ Module } & Frequency & Percentage \\
\hline \multirow{5}{*}{ Internal University } & Biostatistics & 46 & 35.4 \\
\cline { 2 - 4 } & Epidemiology & 64 & 49.2 \\
\cline { 2 - 4 } & Demography (Vital Statistics) & 68 & 52.3 \\
\hline \multirow{5}{*}{ External University } & Biostatistics & 68 & 52.3 \\
\cline { 2 - 4 } & Epidemiology & 102 & 78.5 \\
\cline { 2 - 5 } & Demography (Vital Statistics) & 98 & 75.4 \\
\hline
\end{tabular}

Percentage of Correctly Solving Problems in Three Module

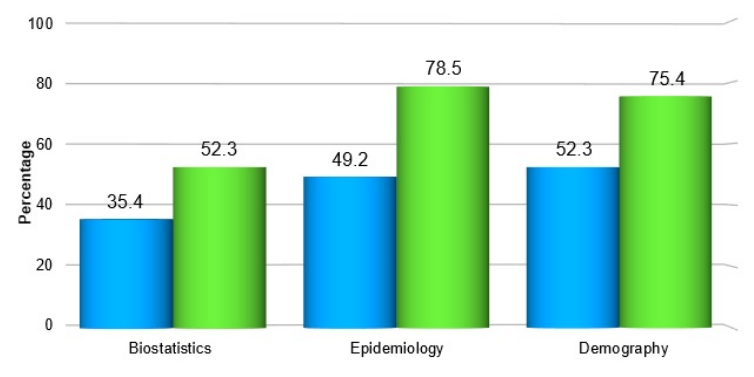

Module

Table-1: Distribution Socio-Demographic 
Fig-1: Distribution of the participants of Correctly solving the problems in the Biostatistics, Epidemiology, and Demography Module.

\section{Table-3: Difficulty Index Values.}

\begin{tabular}{|l|l|l|l|l|}
\hline \multirow{5}{*}{$\begin{array}{l}\text { Sigma distance } \\
\text { from Mean }\end{array}$} & Examination & Biostatistics & Epidemiology & Demography \\
\cline { 2 - 5 } & $\begin{array}{l}\text { Internal } \\
\text { University }\end{array}$ & 0.37 & 0.02 & -0.06 \\
\cline { 2 - 4 } & $\begin{array}{l}\text { External } \\
\text { University }\end{array}$ & -0.06 & -0.79 & -0.69 \\
\hline The difference in Difficulty Between & & 0.35 \\
\hline Internal University Examination & $\begin{array}{l}\text { Biostatistics - } \\
\text { Epidemiology }\end{array}$ & 0.43 \\
\cline { 2 - 4 } & $\begin{array}{l}\text { Biostatistics - } \\
\text { Demography }\end{array}$ & 0.08 \\
\cline { 2 - 4 } & $\begin{array}{l}\text { Epidemiology - } \\
\text { Demography }\end{array}$ & 0.73 \\
\hline \multirow{5}{*}{ External University Examination } & $\begin{array}{l}\text { Biostatistics - } \\
\text { Epidemiology }\end{array}$ & 0.63 \\
\cline { 2 - 4 } & $\begin{array}{l}\text { Biostatistics - } \\
\text { Demography }\end{array}$ & -0.10 \\
\cline { 2 - 4 } & $\begin{array}{l}\text { Epidemiology - } \\
\text { Demography }\end{array}$ & \\
\hline
\end{tabular}

Difficulty Index: The Difficulty of Biostatistics relative to Demography was 1.2 times greater than the difficulty of Biostatistics relative to Epidemiology and the difficulty of Biostatistics relative to Epidemiology was 4.8 times greater than the difficulty of Epidemiology relative to Demography in the Pre-University Examination. In the Final University Examination, the difficulty of Biostatistics relative to Epidemiology was 1.2 times greater than the Biostatistics relative to Demography and the difficulty of Biostatistics relative to Epidemiology was 7.3 times greater than the difficulty of Epidemiology relative to Demography.

\section{Discussion}

Quality Medical care depends upon the development of knowledgeable skilled and competent medical personnel. Any assessment whether formative or summative has an intense effect on learning and is an important variable in directing the learners in a meticulous way [7]. Teaching biostatistics is often considered a difficult task for medical students. However, no one can deny the need for biostatistics, epidemiology, and demography (vital statistics) in the medical curriculum. It is a general compromise regarding the use of basic biostatistics, epidemiology, and demography in medical research and practice.
Each item while being used in the assessment must be evaluated based on the difficulty index. Item difficulty rather than defining difficulty due to some intrinsic characteristic of the item is defined in terms of the frequency with which those taking the test to choose the correct response [5]. The Ahmad [8] study shows that maximum students had a positive response regarding the relevance of different modules to the Medical curriculum with Epidemiology, Biostatistics, and Survey Methodology being the most relevant. Also similarly Kumar $L$ et al [9] found that the majority of the participant believed that biostatistics is important for a career and difficult to understand.

The present study shows that Biostatistics was more difficult than Epidemiology and Demography in Undergraduate Medical student. This study strongly agreed with Butt AK et al that medical institutions should improve their curriculum with better prominence on biostatistical thinking and logics. Research can motivate the clinicians and produce more health researchers by introducing computerized methods and a greater focus on the concept instead of mathematical calculations through formulas [10]

\section{Limitation}

This study was conducted on the Undergraduate Medical Student of one Medical College.

\section{Conclusion}

The study shows that the Biostatistics module was more difficult than other modules for Undergraduate Medical students. The fundamental knowledge of Biostatistics, Epidemiology, and Demography is essential for every medical student for understanding the concept, applications, and importance of Biostatistics, Epidemiology, and Demography.

\section{What does the study add to the existing knowledge?}

01. Every Medical Institute must have Biostatistics and Research Methodology as a discipline at the graduation level. It is essentials to provide conceptual knowledge and it is also important to introduce some computerized statistical packages like SPSS, R programming, Excel, etc to avoid the difficult mathematical calculations and formulae which threaten them to learn Biostatistics. 
02. It may also think of increase the length of lectures and the number of faculties particularly for Biostatistics and Research Methodology.

03. 3) Its recommended to scale up the study in other Medical schools and for the Postgraduate courses to know the variation in difficulty level.

\section{Author contribution}

The authors have an individual contribution to this article. The study design, Research concept done by Dr. Nirmal Verma, while data collection, data arrangement, data analysis, write up was done by Mr. Swapnil Shinkar, and Concept, Methodology, article layout done by Dr. Kamlesh Jain. The authors have no conflict of interest and they read and approved the final manuscript.

\section{Reference}

01. Gupta SC, Kapoor VK. Introduction (Meaning \& Scope). Fundamental of Mathematical Statistics, 11 th revised ed. 2002.

[Crossref]

02. Grady CS, Looney Swa, Steiner RP. A Study of Biostatistics in medical schools in the united states, In Proceedings of the ASA Sections on Statistical Education- 1994. Alexandria, Virginia, USA ASA. 1994;263-265.

[Crossref]

03. Understanding Item Analysis.

Available from: [Article] [Crossref]

04. Singh T, Gupta P, Singh D. Test \& Item AnalysisPrinciples of Medical Education. 3rd ed, New Delhi- Jaypee Brothers Medical Publishers (P) Itd. 2009;70-77.

[Crossref]

05. Matlock Hetzel S. Basic concept in item \& test analysis. Proceeding at annual meeting of the southwest educational research association, Austin. Jan 1997.

[Crossref]

06. Gupta SC, Kapoor VK. Statistics in Psychology and Education. Fundamental of Applied Statistics. 4th revised ed, 2007.

[Crossref]

07. Sarin YK, Khurana M, Natu MV, Thomas AG, Singh T. Item analysis of published MCQs. Indian Paediatrics. 1998;35(11)1103-1105.

[Crossref]
08. Ahmad F, Zehra N, Omair A, Anjum Q. Students opinion regarding application of Epidemiology, Biostatistics and Survey Methodology Courses in Medical research. J Pak Med Assoc. 2009;59(5)307-310.

[Crossref]

09. Kumar L, Shahnawaz K, Choudhary S, Sarkar G, Barman SK \& Singh JB. Attitudes towards biostatistics among post graduate medical students in Kishanganj, Bihar. J Evol Med Dent Sci. $2014 ; 3(3) 758-761$. doi: $10.14260 /$ jemds/2014/1898 [Crossref]

10. Butt $A K$ and Khan AA. Teaching biostatistics and epidemiology in a post graduate medical institution- are we going in the right direction. Eastern Mediterr Health J. 2008;14(5)11921197.

[Crossref] 